\title{
Rubella Antibody Avidity Among Rubella Seropositive Women Attending a Tertiary Care Facility in Nigeria
}

\author{
Sherifat Tinuke Suleiman ${ }^{1 *}$, Rasheed Bakare ${ }^{2}$, Aliyu Ajibola Akanbi II ${ }^{1}$, Adeola Fowotade ${ }^{2}$, \\ Sikiru Abayomi Billiaminu ${ }^{3}$, Kabir Adekunle Durowade ${ }^{4}$
}

\begin{abstract}
Objectives: The aim of this study was to determine the seroprevalence of rubella virus antibodies among women of reproductive age group and assess risk factors of rubella infection.

Materials and Methods: A cross-sectional study was carried out among 285 women aged between 15 and 49 years. Enzyme-linked immunosorbent assay (ELISA) method was used to detect and quantify human immunoglobulin G (IgG) antibodies with avidity for rubella virus in sera of participants. Socio-demographic characteristics of the participants, along with recent and previous history of fever and rash among others were obtained using a questionnaire. Statistical analysis was carried out using SPSS version 16.

Results: Seroprevalence of rubella IgG among women of reproductive age in Ilorin was $92.3 \%$ (95\% CI: 89.2\%-95.4\%). Thus susceptibility rate to rubella infection was $7.7 \%$. Majority (87.1\%) of the IgG seropositive participants had high rubella IgG avidity, implying past rubella infection or reinfections. Seroprevalence was significantly higher among participants from lower educational and socio-economic classes compared with other participants ( $P=.035$ and $P=.023$, respectively). There was a negative correlation between age and rubella specific IgG titer $(P=.000)$. Thus rubella specific IgG titer decreases with increasing age.

Conclusion: There is need for vaccination of susceptible women of reproductive age in Ilorin as the rubella susceptibility rate was higher than the 5.0\% target set by the World Health Organization (WHO) for prevention of congenital rubella syndrome (CRS).

Keywords: Antibody avidity, Nigeria, Rubella, Seroepidemiologic studies
\end{abstract}

\section{Introduction}

Rubella is a vaccine-preventable disease caused by rubella virus. It is usually mild, self-limiting and may be subclinical in more than $50 \%$ of cases (1). However, when acquired during pregnancy, particularly in the first and early second trimester can infect the placenta and foetus resulting in either spontaneous abortion; stillbirth/foetal death, neonate born with congenital rubella syndrome (CRS) or congenital rubella infection (CRI) without congenital defects (2).

CRS may manifest as serious foetal anomalies affecting virtually all organs, especially the eyes, ears, heart and neurological system, making it the leading cause of preventable congenital defects (3). The highest risk of CRS is found in regions with high susceptibility (low seroprevalence) rates among women of childbearing age, as presence of high circulating maternal antibody (minimum serum rubella IgG level of 10-15 $\mathrm{IUml}^{-1}$ ) which indicates immunity to rubella and virtually excludes the possibility of rubella transmission to the foetus (1).

IgG antibody avidity assay (ie, the strength of IgG binding to a multivalent antigen of the virus) is an adjunct test used to distinguish recent from past infections in indi- viduals with IgG antibodies (4). Seroprevalence of rubella varies widely between countries, different parts of the same country and overtime within a particular region of a country (5). The seroprevalence among women of reproductive age is reported as greater than $90 \%$ in most developed countries (6). Rubella seroprevalence in African region range from $71 \%$ to $99 \%$ and varied by age group (range from $84 \%$ to $94 \%$ among women of reproductive age) (6).

Rubella is endemic in Nigeria (7). Studies among women of child bearing age in Nigeria put seroprevalence at $66.6 \%$ in Imo, 77\% in Lagos and $93.5 \%$ in Oyo (8-10). Although data on CRS in Africa are very limited and the true burden is largely unknown, the burden of the chronic disabilities from CRS is high as these disabilities incur high treatment costs thus increasing the public health importance of $\mathrm{Ru}-$ bella (7).

It has been estimated that to prevent CRS the percentage of susceptible women of child-bearing age must not exceed $5.0 \%$ (11). A recent study in this environment however put the seroprevalence of rubella among pregnant women at $16.3 \%$ (12). Thus as part of the control measure, rubella serosusceptibility especially among women 
of reproductive age needs to be assessed with a view to ascertain the risk of CRS. The result of this study would be a useful tool to influence policy on routine immunization among susceptible female groups. This would in turn reduce the menace and the public health impact of CRS since part of preventive measures is screening women of childbearing age for rubella antibodies and immunizing those susceptible (9). This study therefore aims to determine the seroprevalence of rubella among women of reproductive age in Ilorin.

\section{Materials and Methods \\ Study Design}

A cross-sectional descriptive study was carried out among of reproductive age attending general outpatient's clinic at University of Ilorin Teaching Hospital (UITH). Collected blood specimens were analyzed in the same hospital. The inclusion criterion was basically to be consenting females aged 15-49 years. The exclusion criteria included the refusal to participate in the study and previous history of rubella vaccination.

\section{Sampling Method}

Consecutive sampling was used. Subjects who satisfied the inclusion criteria during the study period were included in the study.

Data and Blood Specimen Collection

Each patient was made to sit comfortably. After completion of consent form, the bio data was recorded in a standard questionnaire. Then $4 \mathrm{ml}$ of venous blood was drawn via venepuncture and sample placed in a sterile dry tube. Centrifugation was done at 2000 rotations per minute (rpm) for 5 minutes. Serum was collected in cryotubes and stored at $-20^{\circ} \mathrm{C}$.

\section{Laboratory Analysis of Specimens}

Rubella IgG were assayed using RUB IgG (quantitative) kits (Dia Pro. Diagnostic Bioprobes Srl Columella Milano, Italy) according to the manufacturer's instructions (13).

\section{Data Presentation and Analysis}

All data were entered into computer and analyzed using SPSS version 16 . The prevalence of rubella virus among women of reproductive age was calculated as: $\mathrm{P}=\mathrm{N} 1 / \mathrm{N} 2$ $\times 100 \%$ : Where $\mathrm{P}$ is prevalence; $\mathrm{N} 1$, the total number of women presenting antibodies to the rubella virus; N2, the total number of women tested for antibodies.

Socio-economic index scores to which the participants are entitled to were assigned according to their occupations and educational classes using the Oyedeji socio-economic classification scheme (Appendix I) (14).

In Oyedeji classification scheme, scores ranging I to $\mathrm{V}$ are assigned based on the highest level of education and occupation of participants. The mean of 2 scores (one for the highest level of education and one for occupation) approximated to the nearest whole number was the socio-economic classification (SEC) assigned to the partic- ipants (14). For example, if the participant was an artisan $($ score $=3)$ and the educational attainment was primary 6 $($ score $=4)$, the SEC of this participant was $4+3 / 2=$ to the nearest whole number 4 . Socio-economic index scores range from $\mathrm{I}$ to $\mathrm{V}$, where socio-economic class $\mathrm{I}$ is the highest SEC, while SEC V is the lowest SEC.

Comparison of categorical data was done by chi-square and Fisher exact tests (Fisher exact test was used when the value of any variable is less than 5). Also, rubella-specific IgG antibody levels in the different stratified age groups were compared using one-way analysis of variance (ANOVA). A $P$-value $<.05$ was considered statistically significant.

\section{Results}

A total of 285 women of reproductive age group (15-49 years) resident in Ilorin attending general outpatient clinic at UITH were recruited for the study. The study period was between August 2012 and November 2012.

The mean age of the 285 participants was $28 \pm 7$ years. The demographic characteristic of participants is presented in Table 1. Majority, 223 (78.3\%) participants, were in age group 15-34 years, 144 (50.5\%) single, 189 (66.3\%) practicing Islam and minorities (2.1\%) were in SEC I.

Out of the 285 participants recruited into this study, 263 (92.3\%) were seropositive for rubella specific IgG antibodies while the remaining $22(7.7 \%)$ participants were seronegative. Thus, the overall seroprevalence of rubella IgG antibodies was $92.3 \%$ (95\% CI: 89.2\%-95.4\%).

Table 2 shows the distribution of participants according to

\begin{tabular}{|c|c|c|}
\hline Variable & No. & $\%$ \\
\hline \multicolumn{3}{|c|}{ Age range (years) } \\
\hline $15-24$ & 106 & 37.2 \\
\hline $25-34$ & 117 & 41.1 \\
\hline $35-44$ & 56 & 19.6 \\
\hline$>44$ & 6 & 2.1 \\
\hline \multicolumn{3}{|l|}{ Religion } \\
\hline Christianity & 96 & 33.7 \\
\hline Islam & 189 & 66.3 \\
\hline \multicolumn{3}{|l|}{ Marital status } \\
\hline Single & 144 & 50.5 \\
\hline Married & 140 & 49.1 \\
\hline Widow & 1 & 0.4 \\
\hline \multicolumn{3}{|l|}{ Resident } \\
\hline Ilorin-east & 103 & $36.1^{\mathrm{a}}$ \\
\hline Ilorin-south & 83 & 29.1 \\
\hline Ilorin-west & 99 & 34.7 \\
\hline \multicolumn{3}{|c|}{ Socioeconomic class } \\
\hline I & 5 & $1.8^{\mathrm{a}}$ \\
\hline II & 43 & 15.1 \\
\hline III & 97 & 34.0 \\
\hline IV & 121 & 42.5 \\
\hline V & 19 & 6.7 \\
\hline
\end{tabular}

a Percentages do not add to $100.0 \%$ due to rounding error. 
the stratified age seroprevalence of rubella. The age-specific rubella seroprevalence increased with increasing age. The age-specific rubella seroprevalence was lowest (90.6\%) among participants in the 15-24 years age group and highest (100\%) among those above 44 years. However, the observed increase in rubella seroprevalence with increasing age is not statistically significant $(P=.493)$. A noticeable variability in the values of antibodies was noted in the quantitative analysis for rubella IgG antibodies. The rubella-specific IgG titer ranged between $0.5 \mathrm{IUml}^{-1}$ and values above than $250 \mathrm{IUml}^{-1}$. The lowest rubella-specific IgG titer obtained among the seropositive participants was $22 \mathrm{IUml}^{-1}$, while 155 (58.9\%) had rubella IgG titer above $249 \mathrm{IUml}^{-1}$.

The mean rubella IgG titer of participants in various age groups is presented in Table 3. The highest mean (200.8 $\mathrm{UIml}^{-1}$ ) was found in the age group 15-24 years, while the lowest mean $\left(82.5 \mathrm{UIml}^{-1}\right)$ was among those above 44 years of age.

Rubella IgG titer in the different stratified age groups were compared using one way ANOVA. With an F-ratio of 4.411 , it was concluded that a significant difference exists among different age groups in respect to their rubella specific IgG titer at the.005 significance level.

The Pearson correlation between age and rubella IgG titer was negative at ' $r$ ' value of -0.225 . Thus, the decrease in rubella IgG titer with increasing age is significant $(P=.000)$. Majority $(87.1 \%)$ of the IgG seropositive participants had high rubella IgG avidity as shown in Table 4. The high rubella IgG avidity was found more in older age group than lower age groups. The observed difference was found to be statistically significance $(P=.001)$.

The seroprevalence of rubella in various SEC is presented in Table 5. There was a significant association between rubella IgG status and SEC of participant. Rubella IgG seroprevalence was highest $(100.0 \%)$ among participants in SEC V and lowest (60.0\%) among those in SEC I. There was a significant correlation between rubella IgG seropositivity and SEC $(\mathrm{r}=0.150 ; P=.011)$. Thus, as SEC decreases the rubella seroprevalence increases.

In participants from low SEC, rubella seropositivity was 2.0 times higher than in those from high SEC $(\mathrm{OR}=2.0$; 95\% CI: 1.3-17.2). Thus, seroprevalence was significantly higher among lower SEC than higher SEC $(P=.022)$.

The seroprevalence of rubella IgG among participants according to past history of fever and rash is presented in Table 6. Sixty-six (23.2\%) participants had a past history of fever and rash. Of the 219 participants with no past

Table 2. Stratified-Age Distribution of Rubella IgG Antibodies

\begin{tabular}{|c|c|c|c|c|}
\hline \multirow{2}{*}{ Age (y) } & \multicolumn{2}{|c|}{ Rubella IgG } & \multirow{2}{*}{$\chi^{2}$} & \multirow{2}{*}{$P$ Value } \\
\hline & Positive (\%) & Negative (\%) & & \\
\hline $15-24$ & $96(90.6)$ & $10(9.4)$ & & \\
\hline $25-34$ & 107 (91.4) & $10(8.6)$ & & \\
\hline $35-44$ & $54(96.4)$ & $2(3.6)$ & & \\
\hline$>44$ & $6(100.0)$ & $0(0.0)$ & 2.404 & .493 \\
\hline
\end{tabular}

${ }^{a}$ Row percentage.
Table 3. Age Group Related Mean Rubella lgG Titre

\begin{tabular}{llll}
\hline Age $(\mathbf{y})$ & Mean IgG Titre \pm SD $\left(\right.$ IUml $\left.^{-1}\right)$ & $\mathbf{r}^{\mathrm{a}}$ & $\boldsymbol{P}$ Value \\
\hline $15-24$ & $200.8 \pm 78.8$ & & \\
$25-34$ & $193.6 \pm 80.7$ & & \\
$35-44$ & $183.5 \pm 74.2$ & & \\
$>44$ & $82.5 \pm 55.8$ & -0.225 & $<.001$ \\
\hline
\end{tabular}

a Pearson correlation coefficient.

Table 4. Rubella IgG Avidity by Age

\begin{tabular}{|c|c|c|c|c|}
\hline \multirow{2}{*}{ Age (y) } & \multicolumn{2}{|c|}{ Rubella IgG Avidity } & \multirow{2}{*}{$\mathbf{r}^{\mathrm{a}}$} & \multirow{2}{*}{$P$ Value } \\
\hline & High (\%) ${ }^{b}$ & Low $(\%)^{b}$ & & \\
\hline $15-24$ & $73(76.0)$ & $23(24.0)$ & & \\
\hline $25-34$ & $98(91.6)$ & $9(8.4)$ & & \\
\hline $35-44$ & $52(96.3)$ & $2(3.7)$ & & \\
\hline$>44$ & $6(100.0)$ & $0(0.0)$ & & \\
\hline Total & $229(87.1)$ & (12.9) 34 & -0.277 & $<.001$ \\
\hline
\end{tabular}

a Pearson correlation coefficient.

${ }^{\mathrm{b}}$ Row percentage.

Table 5. Rubella-Specific IgG Antibodies by Socio-Economic Class

\begin{tabular}{|c|c|c|c|c|}
\hline \multirow{2}{*}{ SEC } & \multicolumn{2}{|c|}{ Rubella IgG status } & \multirow{2}{*}{$\mathbf{r}^{\mathrm{a}}$} & \multirow{2}{*}{$P$ Value } \\
\hline & Positive (\%) ${ }^{\mathrm{b}}$ & Negative (\%) ${ }^{b}$ & & \\
\hline I & $3(60.0)$ & $2(40.0)$ & & \\
\hline II & $38(88.4)$ & 5 (11.6) & & \\
\hline III & $88(90.7)$ & $9(9.3)$ & & \\
\hline IV & 115 (95.0) & $6(5.0)$ & & \\
\hline V & $19(100.0)$ & $0(0.0)$ & 0.150 & .011 \\
\hline
\end{tabular}

Abbreviation: SEC, socio-economic classification

a Pearson correlation coefficient.

${ }^{\mathrm{b}}$ Row percentage.

Table 6. Past History of Fever and Rash by Rubella-Specific IgG Antibodies

\begin{tabular}{lcccc}
\hline \multirow{2}{*}{$\begin{array}{l}\text { History of } \\
\text { fever \& rash }\end{array}$} & \multicolumn{2}{c}{ Rubella Specific IgG } & \multirow{2}{*}{ OR (95\% CI) } & \multirow{2}{*}{ P Value $^{\mathrm{a}}$} \\
\cline { 2 - 3 } & Positive (\%) & Negative (\%) & & \\
\hline Yes & $63(95.5)$ & $3(4.5)$ & & \\
No & $200(91.3)$ & $19(8.7)$ & & \\
Total & $263(92.3)$ & $22(7.7)$ & $0.50(0.14-1.75)$ & .270 \\
\hline
\end{tabular}

Abbreviation: OR, Odd ratio.

a Fisher exact test.

history of fever and rash, 200 (91.3\%) had rubella specific IgG antibodies. The rubella IgG seroprevalence increased to $95.5 \%$ for participants with history of fever and rash. However, the increase is not statistically significant $(P=.205)$.

\section{Discussion}

Rubella is a potentially eradicable, vaccine-preventable disease. CRS, a serious consequence of maternal rubella infection during early pregnancy, results in devastating chronic disabilities in foetus. Incidence of CRS depends on the percentage of seronegative (susceptible) women in their reproductive age (11). Seroprevalence of rubella in women of reproductive age in Ilorin according to IgG ru- 
bella assay was found to be $92.3 \%$ (95\% CI: 89.2\%-95.4\%). Thus, the percentage of seronegative women of reproductive age was $7.7 \%$ which is higher than the $5.0 \%$ estimated value for elimination of CRS (11). This is an important finding for susceptible women who might acquire rubella infection during pregnancy leading to CRI in their babies. The high seroprevalence could be due to the fact that rubella virus is wide spread, primarily infecting young children and by the age of 15 years most will have immunity from natural infection (6). Rubella vaccine is not included in Nigeria's Immunization schedule; this further suggests that the presence of antibodies is related to natural infection.

Across the globe, there is considerable variation in the seroprevalence of rubella among women of reproductive age. In a review of rubella epidemiology in Africa by Goodson et al (6), rubella seropositivity among women of reproductive age ranged between $84 \%$ and $94 \%$. The rubella seropositivity obtained in this study is within this range. It is also similar to $93.5 \%$ obtained in a previous study among women of child bearing age in Oyo state by Adesina et al (8) and 90.1\% obtained among women 15-45 years of age in Senegal by Dromigny et al (15). Conversely, it is at variance from a previous study by Agbede et al (12) among pregnant women at UITH, Ilorin where a value of $16.3 \%$ was obtained. It is also higher than $77.0 \%$ reported among nonvaccinated women by Onyenekwe et al (10) in Lagos, Nigeria and $88.6 \%$ among women of reproductive age in Cameroon (6). The observed differences might be because of the differences in study population, sample size and study period. In addition, the observed variation might be due to a recent outbreak. The risk of rubella and subsequently CRS is highest in countries with high susceptibility rate among women of childbearing age, which might be the case in Ilorin as earlier reported by Agbede et al (12) 3 year ago when the susceptibility among pregnant women was $83.7 \%$, thus a recent epidemic might have occurred.

In places where susceptibility rate of rubella virus in women of reproductive age is low, this may reflect low socio-economic status, recent outbreak of rubella or intense circulation of virus in younger age group (16). If a recent outbreak has occurred, then a high number of cases of CRS may have occurred, as the risk of CRS may increase by tenfold following epidemic (17). Thus, it may be useful to assess the burden of CRS in this environment.

Rubella IgG seropositivity rate increased with increasing age, but it was not statistically significant. Studies by Dayan et al (18) and Palihawadana et al (19) found significant increasing seroprevalence of rubella with increasing age. A study by Pehlivan et al (20) among Turkish women however, reported no significant relationship between age and rubella seroprevalence.

Conversely, a significant difference exists among different age groups in respect to their rubella-specific IgG titer $(P=.005)$. Rubella-specific IgG antibodies titer significantly decrease with increasing age $(P=.000)$ which might be due to natural waning of antibodies with age. Although rubella IgG antibodies persist for at least 20 years, and probably for life, they may decline to very low levels in old age. The mean antibody titer was higher in younger age group than in older participants. Similar findings were reported by other studies, among vaccinated and nonvaccinated populations $(21,22)$.

To distinguish participants with reinfection from those with primary infection, since there were no prescreening sera available, the rubella IgG avidity were determined. The IgG antibody avidity (ie, the strength of IgG binding to a multivalent antigen of the virus) is an adjunct test used to distinguish recent from past infections in individuals with significant IgG antibodies (14). In the acute phase of an immune response, the IgG antibody generated by the antigen has low avidity (below 50\%). This is because the antibody binds with less strength to the antigen. The strength of the antibody-antigen bonds increases within 2-4 months after infection, reflected in an avidity reading of greater than $50 \%$.

Sera from cases of recent rubella primary infection have low IgG avidity, while sera taken from participants with past infection (including cases of rubella reinfection) have higher avidity (4). Thirty-four (11.9\%) participants had a low avidity IgG among which 23(67.6\%) were aged 15-24 years. Low avidity rubella IgG antibodies were significantly more in younger age group than older age group $(P=.001)$. The group with low avidity IgG are at risk of a reinfection which carries a low (8\%) risk for having children with CRS (18). It may also indicate recent rubella infections in $11.9 \%$ participants which are in their reproductive age. This particular proportion of women in their repoductive age had a chance of having a child with CRS if they were to be in early stage of pregnancy. Five percent of all reported rubella infection in Africa occur in women of reproductive age (6).

Rubella seroprevalence were compared within various SECs. Significantly higher rubella seroprevalence was observed among participant from low SEC compared with those from high SEC. This could be due to association between close contact, overcrowding or poor environment and hygiene and acquisition of rubella infection in participants from low SEC. Similar findings have also been reported by Raveendran et al (23).

Rubella is a common cause of maculopapular rash with fever. However, no significant differences were observed in the rubella antibody seropositivity of participants according to past history of fever and rash. This can be explained by the fact that rubella infections could be asymptomatic or symptomatic (1). Moreover some with previous history of fever and rash may not remember. Previous studies have presented no significant association between rubella seroprevalence and history of fever and rash.

\section{Conclusion}

The seroprevalence of rubella in women of reproductive age in Ilorin was $92.3 \%$. There is a significant risk of rubella infection among women of reproductive age in Ilorin as rubella susceptibility rate in this study was $7.7 \%$. A few 
$(8.7 \%)$ of the participants had a low rubella IgG avidity which connotes a recent rubella infection. There is therefore a need for rubella vaccination among susceptible women. Thus, this study recommends routine preconception rubella screening for women of reproductive age in Nigeria and rubella vaccination should be provided for those susceptible.

Considerations should also be made on the necessity to introduce rubella vaccination into the current National Programme on Immunization in Nigeria as soon as greater than $80 \%$ measles coverage is achieved as suggested by World Health Organization (WHO). Finally, effective rubella/CRS surveillance should be put in place in this country.

\section{Ethical Issues}

Ethical clearance was obtained from the Ethics and research committee of UITH Ilorin. Informed, written and signed consent was obtained from participants.

\section{Financial Support}

This research was supported by University of Ilorin Teaching hospital, Ilorin.

\section{Conflict of Interests}

The authors declare that they have no competing interests.

\section{Acknowledgments}

We do acknowledge the efforts of Dr. Saka Aisha, Mrs. Lawal Mariam and Dr. Wahab of University of Ilorin Teaching Hospital, toward the successful completion of this work.

\section{References}

1. Mendelson E, Aboudy Y, Smetana Z, Tepperberg M, Grossman Z. Laboratory assessment and diagnosis of congenital viral infections: rubella, cytomegalovirus (CMV), varicella zoster Virus (VZV), herpes simplex virus (HSV), parvovirus B 19 and human immunodeficiency virus (HIV). Reprod Toxicol. 2006;21(4):350-382. doi:10.1016/j. reprotox.2006.02.001.

2. Best J, Reef S. Immunization, vaccines and biologicals. World Health Organization; 2008. http://www.who. int/immunization/topics/rubella/en/index.html. Accessed January 2012.

3. Robertson SE, Featherstone DA, Gacic-Dobo M, Hersh BS. Rubella and congenital rubella syndrome: global update. Rev Panam Salud Publica. 2003;14(5):306315. doi:10.1590/s1020-49892003001000005.

4. Miller CL. Rubella in developing world. Epidemiol Infect. 1991;107(1):63-68. doi:10.1017/ s0950268800048688.

5. Hyde TB, Kruszon-Moran D, McQuillan GM, Cossen C, Forghani B, Reef SE. Rubella immunity level in United States population; has the threshold of viral elimination been reached? Clin Infect Dis. 2006;43 (suppl 3):S146-S150. doi:10.1086/505947.
6. Goodson JL, Masresha B, Dosseh A, et al. Rubella epidemiology in Africa in the prevaccine era, 20022009. J Infect Dis. 2011;204(suppl 1):S215-S225. doi:10.1093/infdis/jir108.

7. Ogunsola S. Rubella virus: an underestimated pathogen in Nigeria. Pathology Forum. 2009;1(1):12.

8. Adesina OA, Adeniji JA, Adeoti MO. Rubella IgG antibody in women of childbearing age in Oyo State. African J Clin Exp Microbiol. 2008;9(2):78-81. doi:10.4314/ajcem.v9i2.7486

9. Gomwalk NE, Ezeronye OU. Sero-epidemiology of rubella in Imo State of Nigeria. Trans R Soc Trop Med Hyg. 1985;79(6):777-780. doi:10.1016/00359203(85)90114-2.

10. Onyenekwe CC, Kehinde-Agbeyangi TA, Ofor US, Arinola OG. Prevalence of rubella-IgG antibody in women of childbearing age in Lagos, Nigeria. West Afr J Med. 2000;19(1):23-26.

11. Lo Giuidice D, Cannavo G, Capua A, et al. Eliminating congenital rubella; A seroepidemiological study on women of childbearing age and MMR vaccine coverage in newborns. J Prev Med Hyg. 2009;50(4):236-240.

12. Agbede OO, Adeyemi OO, Olatinwo AW, Salisu TJ, Kolawole OM. Sero-Prevalence of antenatal rubella in UITH. Open Pub Health J. 2011;4:10-16.

13. Dia Pro. Diagnostic bioprobes srl. Rubella IgG, IgM and avidity kits manufacturing company, 'Insert'. https://www.diapro.it/. Accessed August 2012.

14. Oyedeji G. Is it well with the Nigerian child? Obafemi Awolowo University Ile Ife, Nigerian inaugural lecture series 171; 2000. p. 13.

15. Dromigny JA, Nabeth P, Perrier Gros Claude JD. Evaluation of the seroprevalence of rubella in the region of Dakar (Senegal). Trop Med Int Health. 2003;8(8):740-743.

16. Barreto J, Scramento I, Robertson SE, et al. Antenatal rubella serosurvey in Maputo, Mozambique. Trop Med Int Health. 2006;11(4):559-564. doi:10.1111/ j.1365-3156.2006.01577.x.

17. Best J, Icenogle J, Brown D. Rubella. In: Zuckerman A, Banatvala J, Schoub B, Griffiths P, Mortimer P, eds. Principles and Practice of Clinical Virology. 6th ed. Chichester: John Wiley \& Sons; 2009:561-592.

18. Dayan GH, Panero MS, Urquiza A, et al. Rubella and measles seroprevalence among women of childbearing age, Argentina, 2000. Epidemiol Infect.2005;133(5):861-869. doi:10.1017/ s0950268805004437

19. Palihawadana P, Wickremasinghe AR, Perera J. Seroprevalence of rubella antibodies among pregnant females in Sri Lanka. Southeast Asian J Trop Med Pub Health. 2003;34(2):398-404.

20. Pehlivan E, Karaoglu L, Ozen M, et al. Rubella seroprevalence in an unvaccinated pregnant population in Malatya, Turkey. Public Health 2007;121(6):462-8.

21. Lin CC, Yang CY, Shih YL, et al. Persistence and titer changes of rubella virus antibodies in primiparous 
women who had been vaccinated with strain RA 27/3 in junior high school. Clin Vaccine Immunol. 2012;19(1):1-4. doi: 10.1128/CVI.05334-11.

22. Poethko-Müller C, Mankertz A. Seroprevalence of measles-, mumps- and rubella-specific IgG antibodies in German children and adolescents and predictors for seronegativity. PLoS One 2012;7(8):e42867. doi: 10.1371/journal.pone.0042867.

23. Raveendran V, Pragash DS, Manju IAS, Shaker IA, Rayapu V. Seroprevalence of rubella in antenatal women in and arround Kirumampakkam, Puducherry. Int J Bioassay. 2012;1(10):74-78.

Appendix 1. Socio-Economic Classification Scheme by Oyedeji (14)

\begin{tabular}{|c|c|}
\hline \multicolumn{2}{|c|}{ For Occupation } \\
\hline Class & Occupation \\
\hline I & Senior public servants, professionals, managers, large scale traders, businessmen and contractors. \\
\hline II & Intermediate grade public servants and senior school teachers. \\
\hline III & Junior school teachers, drivers, artisans. \\
\hline IV & Petty traders, labourers, messengers. \\
\hline $\mathrm{V}$ & Unemployed, full-time housewife, students and subsistence farmers. \\
\hline \multicolumn{2}{|c|}{ Educational status } \\
\hline Class & Educational attainment \\
\hline I & University graduates or equivalents \\
\hline II & School certificate holders, ordinary level (GCE) who also had teaching or other professional training. \\
\hline III & School certificate or grade II teacher's certificate holders. \\
\hline IV & Modern three and primary six certificate holders. \\
\hline V & Those who could either just read and write or were illiterate. \\
\hline
\end{tabular}

Copyright $\odot 2015$ The Author(s); This is an open-access article distributed under the terms of the Creative Commons Attribution License (http://creativecommons.org/licenses/by/4.0), which permits unrestricted use, distribution, and reproduction in any medium, provided the original work is properly cited. 